\title{
Congenital Renal Hypoplasia
}

National Cancer Institute

\section{Source}

National Cancer Institute. Congenital Renal Hypoplasia. NCI Thesaurus. Code C123026.

The underdevelopment of otherwise normal renal parenchyma, characterized by decreased nephron size and possibly a decreased number of nephrons at birth. 